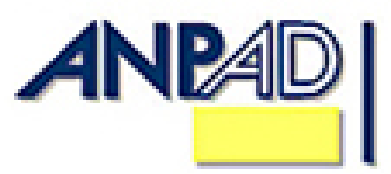

Disponível em

http://www.anpad.org.br/rac

RAC, Curitiba, v. 14, n. 6, art. 4,

pp. 1054-1072, Nov./Dez. 2010

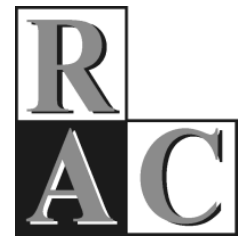

\title{
Felicidade no Trabalho: Relações com Suporte Organizacional e Suporte Social
}

\author{
Happiness at Work: Relations with Organizational Support and Social Support
}

Tatiane Paschoal *

Doutora em Psicologia Social, do Trabalho e das Organizações pela UnB. Professora do Departamento de Administração da UnB, Brasília/DF, Brasil.

Cláudio V. Torres

Doutor em Psicologia Organizacional e Industrial pela California School of Professional Psychology, EUA. Professor do IP/UnB, Brasília/DF, Brasil.

Juliana Barreiros Porto

Doutora em Psicologia pela UnB. Professora do IP/UnB, Brasília/DF, Brasil.

* Endereço: Tatiane Paschoal

Universidade de Brasília, ICC Norte Bloco B, sala B1-576, Depto. de Administração, Campus Universitário Darcy Ribeiro, Asa Norte, 70910-900, Brasilia/DF. E-mail: tatipas@yahoo.com

Copyright (C) 2010 RAC. Todos os direitos, até mesmo de tradução, são reservados. É permitido citar parte de artigos sem autorização prévia, desde que seja identificada a fonte. 


\title{
RESUMO
}

O presente estudo teve como objetivo testar o impacto do suporte organizacional e do suporte social sobre o bem-estar no trabalho. Este construto contemplou tanto o afeto quanto a experiência de realização e expressão pessoal no trabalho. Um total de 403 funcionários de uma organização pública do Distrito Federal respondeu à Escala de Bem-Estar no Trabalho e à Escala de Suporte Organizacional Percebido. O primeiro instrumento contempla o afeto do trabalhador, operacionalizado como emoções e humores positivos e negativos no trabalho, e a realização pessoal no trabalho. O segundo instrumento contempla um fator de suporte social e quatro fatores de suporte organizacional: gestão do desempenho, carga no trabalho, suporte material e ascensão, promoção e salários. Os dados foram analisados por meio de regressão múltipla padrão. Os resultados indicaram que o suporte organizacional e o suporte social têm impacto direto no bem-estar. Gestão do desempenho foi o principal preditor de afeto positivo e realização no trabalho. Carga no trabalho foi o principal preditor de afeto negativo no trabalho. Implicações dos resultados e limitações do estudo são discutidas no texto.

Palavras-chave: bem-estar no trabalho; afeto no trabalho; eudaimonia; suporte organizacional.

\begin{abstract}
The objective of the present study was to test the impact of organizational and social support on well-being at work. To achieve this, the well-being construct included the concepts of affect, accomplishment experience and work-related personal experience. A total of 403 employees of a public organization in the Brazilian Federal District responded to the Work Well-Being Scale, and to the Perceived Organizational Support Scale. The former evaluates the positive and negative emotions towards at work, as well as the personal accomplishment at work. The latter includes a social support factor and four other factors relating to organizational support: performance management, workload, material support, and work growth, promotion and salary. Data were analyzed with the use of multiple regression, and the results indicated that organizational support and social support have a direct impact on well-being. Performance management was the main predictor for positive affect, and for accomplishment at work. Workload was the main predictor of negative work affect. The implications and limitations of the study are discussed.
\end{abstract}

Key words: work well-being; affect at work, eudaimonia; organizational support. 


\section{INTRODUÇÃO}

Atualmente, os ativos intangíveis da organização, como as pessoas que a compõem, são considerados os seus mais importantes diferenciais competitivos (Oliveira \& Limongi-França, 2005). Diante da concorrência crescente no mundo dos negócios e das demandas do ambiente de trabalho pela excelência no funcionamento de indivíduos, grupos e instituições, as organizações têm-se preocupado em valorizar seus empregados e criar as condições necessárias para o seu bom desempenho e satisfação. A premissa de que a felicidade pessoal pode ser alcançada por meio do trabalho estimula os gestores de pessoas e os estudiosos do comportamento organizacional a identificarem estratégias eficazes na promoção do bem-estar no ambiente laboral.

A importância do trabalho na vida das pessoas tem sido consistentemente apontada na literatura científica (Codo, 1999; Estramiana, 1992; Warr, 1987). Em sua revisão das principais funções psicossociais do trabalho, Estramiana (1992) demonstra que, além de prover os meios necessários para a subsistência humana, o trabalho ajuda a definir o status que o indivíduo assume na sociedade e a sua própria identidade pessoal, permite a organização do tempo e possibilita o enriquecimento das redes de relações sociais.

Mas quais características organizacionais e laborais aumentam as experiências de bem-estar? Como isso ocorre? Apesar da importância de se compreender a felicidade contextualizada no trabalho, há poucos modelos teóricos e empíricos sobre as variáveis que a determinam. As principais pesquisas na área referem-se a fenômenos apenas relacionados ao bem-estar no trabalho, como o estresse ocupacional e o esgotamento profissional (burnout).

Tanto o estresse ocupacional quanto o esgotamento profissional dizem respeito a experiências negativas vivenciadas pelo trabalhador. O campo de estudo do estresse ocupacional tem como preocupação principal a compreensão da relação entre estímulos do ambiente de trabalho e respostas não saudáveis dos trabalhadores (Beehr, 1998). O esgotamento profissional, por sua vez, é considerado síndrome psicológica decorrente da tensão emocional crônica no trabalho, experiência que gera atitudes e sentimentos negativos no relacionamento do indivíduo com o seu trabalho (Maslach \& Jackson, 1986; Tamayo \& Tróccoli, 2002). Esses dois construtos relacionados ao bemestar referem-se claramente a experiências negativas vivenciadas no contexto laboral e não abordam diretamente as experiências positivas do trabalhador.

O presente estudo teve como objetivo testar o impacto do suporte organizacional e do suporte social das diferentes dimensões do bem-estar no trabalho. Suporte organizacional e suporte social têm sido relacionados a diferentes fenômenos do campo do comportamento organizacional. Suporte organizacional diz respeito às crenças do trabalhador sobre a retribuição da organização aos seus esforços para alcançar metas organizacionais (Eisenberger, Huntington, Hutchison, \& Sowa, 1986). Suporte social refere-se ao apoio que o indivíduo recebe do chefe e dos colegas de trabalho (Seidl \& Tróccoli, 2006). Seriam essas duas variáveis antecedentes do bem-estar no trabalho?

Quanto aos fins, o presente estudo pode ser classificado como explicativo e, quanto aos meios, consistiu em uma pesquisa de campo. A seguir, são apresentadas as conceituações das variáveis abordadas e a literatura pertinente a cada tópico.

\section{BEM-ESTAR NO TRABALHO}

A tendência recente da literatura em explorar os aspectos claramente positivos das pessoas e das organizações tem aproximado os termos felicidade e bem-estar (Albuquerque \& Tróccoli, 2004; Warr, 2007). De acordo com Albuquerque e Tróccoli (2004), o campo do bem-estar refere-se ao estudo científico da felicidade. Entre os pesquisadores do comportamento organizacional, porém, a 
palavra felicidade costuma ser evitada e em seu lugar são adotados termos menos populares e mais acadêmicos, como afeto e bem-estar. Segundo Warr (2007), o uso do termo felicidade oferece algumas vantagens aos pesquisadores. Em primeiro lugar, o termo felicidade levanta elementos filosóficos e conceituais frequentemente excluídos das pesquisas do bem-estar. Em segundo lugar, as pesquisas do bem-estar abordam o fenômeno de strain, relacionado aos afetos negativos, ou à ausência de experiências negativas, o que agrega uma tônica negativa ou neutra ao campo de estudo. A concepção do bem-estar como felicidade, por sua vez, enfatiza claramente os aspectos positivos da experiência do trabalhador e agrega aos termos uma conotação positiva. $\mathrm{O}$ presente estudo segue a tendência atual da literatura científica e trata o bem-estar como sinônimo de felicidade (Albuquerque \& Trócolli, 2004; Deci \& Ryan, 2008; Warr, 2007; Waterman, Schwartz, \& Conti, 2008).

Como consequência das correntes do bem-estar geral, a literatura organizacional tem definido e operacionalizado o bem-estar no trabalho em termos hedônicos ou eudaimônicos. Autores que adotam abordagem hedônica tratam o bem-estar como experiência cumulativa de afetos no trabalho. Definem o fenômeno em termos das emoções e humores do trabalhador (Daniels, 2000). O bem-estar é mais elevado quanto mais frequentes e intensas forem as emoções positivas e quanto mais elas prevalecerem sobre o afeto negativo do trabalhador.

A abordagem eudemonista do bem-estar enfatiza as experiências de realização pessoal e de expressão dos potenciais individuais (Ryan \& Deci, 2001; Waterman, 1993). No campo do bem-estar geral, a proposta de Ryff (1989) tem sido a principal referência teórica. De acordo com a autora, o bem-estar deve ser considerado como o funcionamento positivo do indivíduo e está estruturado em torno de seis dimensões: autoaceitação, relação positiva com os outros, autonomia, controle do ambiente, propósito na vida e crescimento pessoal. Horn, Taris, Schaufeli e Scheurs (2004) baseiam-se na proposta de Ryff (1989) e definem o bem-estar a partir das seguintes variáveis: afeto, exaustão emocional, satisfação no trabalho, comprometimento organizacional, autonomia, aspiração, competência profissional, despersonalização, cansaço cognitivo e presença ou ausência de queixas psicossomáticas.

A tendência recente na literatura vem sendo a inclusão de elementos hedônicos e eudaimônicos nas conceituações de bem-estar (Ryan \& Deci, 2001; Seligman \& Csikszentmihalyi, 2000; Warr, 2007; Waterman et al., 2008). A consideração exclusiva dos afetos pode ser avaliada como visão limitada da felicidade, que exclui uma experiência subjetiva de extrema importância: a realização e a expressão dos potenciais e metas individuais (Tiberius, 2004).

De acordo com Waterman (1993) e Waterman et al. (2008), quando uma pessoa vivencia expressão e realização pessoal, ela sente mais afetos positivos do que negativos. Por outro lado, há muitos outros caminhos para a felicidade hedônica além da realização pessoal, como, por exemplo, quando afetos positivos acompanham a satisfação de necessidades físicas e sociais (Waterman, 1993). Em tais situações, o indivíduo pode não experimentar a expressão e a realização pessoal.

As experiências de expressão e realização pessoal costumam ser vivenciadas, quando o indivíduo se envolve intensamente com um empreendimento, tem sentimento intenso de estar vivo e completo, quando engajado em determinadas atividades, avalia que fez o que realmente queria fazer e percebe que consegue expressar seu verdadeiro eu. A expressão pessoal e a autorrealização referem-se essencialmente à experiência individual de realização dos próprios potenciais, na forma de desenvolvimento de habilidades e talentos e de avanço de propósitos de vida (Waterman, 1993).

Warr (2007) afirma que existem dois tipos de felicidade e que ambos são fundamentais para a adequada compreensão do fenômeno. O primeiro corresponde aos sentimentos de prazer vivenciados pelo indivíduo e pode ser relacionado à felicidade hedônica; o segundo refere-se ao que foi denominado de autovalidação e se relaciona com a felicidade eudaimônica.

Quanto à felicidade hedônica, emoções de prazer e excitação combinam-se para determinar a tônica afetiva do indivíduo. Emoções de prazer, entusiasmo e conforto são representantes do afeto positivo e indicam alto bem-estar, enquanto emoções de desprazer, ansiedade e depressão representam o afeto 
negativo e indicam baixo bem-estar. Quanto à autovalidação, o desenvolvimento de atributos pessoais, a exploração do próprio potencial e a expressão pessoal são seus aspectos constituintes (Warr, 2007).

A experiência hedônica, caracterizada pelas emoções positivas e negativas no trabalho, tem-se revelado como elemento essencial do bem-estar no trabalho, mesmo nos estudos conduzidos por psicólogos que adotam uma visão multidimensional do fenômeno (Horn et al., 2004). Ao mesmo tempo, as experiências de realização e expressão pessoal, que se referem ao elemento eudaimônico da felicidade, vêm ganhando força entre importantes teóricos da área (Warr, 2007; Waterman, 1993; Waterman et al., 2008). Waterman (1993) e Waterman et al. (2008) demonstram que situações diferentes levam a experiências de bem-estar distintas e que tanto as emoções prazerosas quanto a percepção de realização e expressão são fundamentais para a felicidade.

É importante destacar que autores como Warr (2007), Waterman (1993) e Waterman et al. (2008) enfatizam as experiências subjetivas de expressão e realização na definição da eudaimonia, ao contrário do modelo de Ryff (1989), que considera elementos como relações sociais positivas, percepção de controle do ambiente e competência. Esses elementos podem configurar-se como antecedentes da felicidade. Por exemplo, autonomia, competência e relacionamento são três necessidades psicológicas básicas; quando satisfeitas, levam ao bem-estar (Daniels, 2000; Ryan \& Deci, 2001). Quando se conceitua um construto, é importante separá-lo de seus antecedentes e consequentes.

Paschoal e Tamayo (2008), com base na proposta de Waterman (1993) e de forma compatível com a proposta de Warr (2007), conceituam o bem-estar no trabalho como a prevalência de emoções positivas no trabalho e a percepção do indivíduo de que, no seu atuar, expressa e desenvolve seus potenciais e avança no alcance de suas metas de vida. O bem-estar no trabalho, deste modo, inclui tanto aspectos afetivos (emoções e humores) quanto cognitivos (percepção de realização) e engloba os pontos centrais da abordagem hedonista e da abordagem eudemonista. Em termos operacionais, o bem-estar no trabalho pode ser organizado em torno de três fatores: afeto positivo, afeto negativo e realização pessoal no trabalho. Os dois primeiros referem-se aos elementos hedônicos do bem-estar no trabalho e o último refere-se aos elementos eudaimônicos. Tal definição de bem-estar no trabalho é adotada no presente estudo.

Como o estudo científico do construto específico da felicidade no trabalho é recente e ainda é possível encontrar conceituações baseadas em estresse, saúde mental e construtos correlatos, a identificação e sistematização de antecedentes do bem-estar no trabalho consiste em uma tarefa desafiadora.

De forma geral, a literatura organizacional demonstra que variáveis organizacionais e laborais são os principais preditores do bem-estar no trabalho. Variáveis como oportunidades de controle e autonomia (Kelloway, Gottlieb, \& Barham, 1999), uso de habilidades profissionais (Wilson, DeJoy, Vandenberg, Richardson, \& McGrath, 2004), conflito entre trabalho e família (Williams, Suls, Alliger, Learner, \& Wan, 1991), percepção de ambiguidade no ambiente (Pollard, 2001), relações sociais e suporte social (Totterdell, Wall, Holman, Diamond, \& Epitropaki, 2004) e percepção de justiça organizacional (Weiss, Suckow, \& Cropanzano, 1999) têm sido empiricamente relacionadas a algum indicador de bem-estar. Segundo Warr (2007), todos os contextos de trabalho remunerado podem ser descritos a partir de 12 características centrais. São elas: oportunidade de controle pessoal, oportunidade para o uso de habilidades, metas geradas pelo ambiente, variedade do trabalho, clareza do ambiente, contato social, disponibilidade de dinheiro, segurança física, posição social, suporte do supervisor, oportunidades na carreira e equidade. Além de diferenciar um ambiente de trabalho de outro, cada uma dessas características influencia muitos comportamentos organizacionais, a saúde mental e o bem-estar do trabalhador (Warr, 2007).

Cabe ressaltar que a literatura sobre antecedentes do bem-estar no trabalho está constituída, principalmente, de estudos que abordam as emoções e humores no trabalho, que consistem na dimensão hedônica do bem-estar (Totterdell et al., 2004; Weiss et al., 1999). Muitos estudos enfatizam ainda emoções negativas, como ansiedade, tensão e depressão (Kelloway et al., 1999). A 
dimensão eudaimônica do bem-estar no trabalho, que tem sido indicada como um elemento central na felicidade, não costuma ser incluída nas pesquisas.

O presente estudo busca cobrir essas lacunas do campo do bem-estar relativo ao contexto laboral e propõe a investigação do impacto de variáveis organizacionais sobre os aspectos hedônicos (afeto positivo e afeto negativo) e eudaimônicos (realização) do bem-estar no trabalho. As variáveis de interesse são o suporte organizacional e social no trabalho, que consistem em características de trabalho percebidas pelo trabalhador.

\section{Suporte Organizacional e Suporte Social no Trabalho}

No contexto do trabalho, os empregados desenvolvem crenças sobre a retribuição da organização aos seus esforços para alcançar metas organizacionais (Eisenberger et al., 1986). Este fenômeno é denominado de percepção de suporte organizacional e depende da frequência, da intensidade e da sinceridade dos elogios, da aprovação e das recompensas que a organização dirige aos seus membros. Os trabalhadores desenvolvem crenças globais acerca de quanto a organização cuida do seu bem-estar e como valoriza os seus esforços.

Eisenberger et al. (1986) utilizaram as teorias de troca social para propor que os empregados desenvolvem com a organização uma relação marcada por expectativas de reciprocidade, segundo as quais as pessoas devem ajudar aqueles que as ajudaram. $\mathrm{O}$ trabalhador tem obrigação de apresentar bom desempenho e comprometer-se com a organização; esta, por sua vez, tem obrigações legais, financeiras e morais com seus membros (Oliveira-Castro, Borges-Andrade, \& Pilati, 1999). Segundo Eisenberger et al. (1986), a percepção de suporte organizacional ocorre a partir de um processo de personificação da organização, o que significa que os empregados veem as ações dos agentes organizacionais como ações da própria organização. As crenças sobre as retribuições organizacionais dependem do mesmo processo de atribuição utilizado para inferir o comprometimento de outras pessoas nas relações sociais. Segundo Oliveira-Castro et al. (1999), o trabalhador só desenvolve percepções favoráveis do suporte organizacional, quando julga que as retribuições organizacionais são sinceras, bem intencionadas e não manipulativas.

Oliveira-Castro et al. (1999) investigaram a estrutura do suporte organizacional e desenvolveram uma medida para avaliação do fenômeno. A percepção de suporte organizacional foi estruturada em torno de quatro dimensões: gestão de desempenho, carga de trabalho, suporte material ao desempenho e ascensão, promoção e salários.

A gestão do desempenho refere-se à opinião dos trabalhadores sobre as práticas organizacionais de gerenciamento do desempenho dos funcionários, como estabelecimento de metas, valorização de novas ideias, conhecimento de dificuldades associadas à execução das tarefas e o esforço organizacional de atualização de seus empregados em face das novas tecnologias. A carga de trabalho refere-se às exigências e à sobrecarga de tarefas atribuídas aos funcionários, devido a altas demandas de produção. O suporte material reflete a percepção do indivíduo sobre a disponibilidade, adequação, suficiência e qualidade dos recursos materiais e financeiros fornecidos pela organização para apoiar a execução eficaz das tarefas. Além disso, o suporte material engloba os esforços organizacionais de modernização e dinamização dos processos de trabalho e a qualificação de mão-de-obra interna. Finalmente, a dimensão ascensão, promoção e salários refere-se à percepção do indivíduo acerca das práticas organizacionais de retribuição financeira, promoções e ascensão funcionais (Oliveira-Castro et al., 1999).

Pinheiro (2002) apontou a importância do suporte social recebido no trabalho para a predição de variáveis diversas relacionadas a esse contexto, como elementos da saúde do trabalhador. Assim, partiu das dimensões apresentadas por Oliveira-Castro et al. (1999) para propor a inclusão de mais dois fatores na avaliação do suporte organizacional: gestão da chefia e suporte social no trabalho. As duas dimensões adicionais buscam cobrir a dimensão relacional do suporte. 
A inclusão de uma dimensão relacional à definição de percepção do suporte organizacional vai ao encontro da proposta de Oliveira-Castro et al. (1999), que defende as crenças do trabalhador sobre a retribuição da organização como um todo e não a retribuição de seus agentes, como chefes e colegas de trabalho. O agente das ações de retribuição na definição de suporte organizacional consiste na própria organização. É possível que a proposta de Pinheiro (2002) envolva dois fenômenos distintos: (a) percepção de suporte organizacional, composta pelos fatores de gestão de desempenho, carga de trabalho, suporte material ao desempenho e ascensão, promoção e salários; (b) percepção de suporte social no trabalho, constituída pelos fatores de gestão da chefia e suporte social. No presente estudo, são consideradas tanto a percepção de suporte organizacional quanto a percepção de suporte social no trabalho.

E por que as percepções de suporte organizacional e de suporte social poderiam contribuir para a compreensão do bem-estar no trabalho? Para responder à questão levantada, é necessário enfatizar que as condições de trabalho têm sido apontadas como importantes determinantes do bem-estar (Tamayo \& Tróccoli, 2002; Warr, 2007). Ainda que a percepção de suporte organizacional e a percepção de suporte social envolvam agentes diferentes, os dois fenômenos podem ser considerados como a percepção do empregado sobre características e condições de trabalho.

Apesar de não terem sido encontrados estudos sobre a relação entre suporte organizacional e as dimensões hedônicas e eudaimônicas do bem-estar, um dos aspectos que pode ser identificado no suporte organizacional consiste nas características e condições de trabalho derivadas de ações da organização dirigidas aos seus membros. Tais ações poderiam influenciar diretamente as emoções vivenciadas pelo trabalhador. Por exemplo, ações relacionadas à carga de trabalho poderiam suscitar diretamente experiências afetivas durante o dia a dia organizacional. Além disso, as ações organizacionais, como aquelas relacionadas à gestão do desempenho e ascensão profissional, estão associadas a práticas que poderiam favorecer a experiência de expressão e realização pessoal no trabalho. O suporte organizacional envolve ainda a ideia de retribuição organizacional aos esforços do trabalhador. A percepção do trabalhador de que a organização oferece condições compatíveis com seus esforços devem influenciar diretamente os resultados como as emoções no trabalho.

Em relação ao suporte social no trabalho, a literatura tem indicado que os aspectos sociais presentes na organização influenciam os afetos no trabalho e construtos relacionados ao bem-estar. Segundo Seidl e Tróccoli (2006), o suporte social influencia positivamente o bem-estar por amenizar os eventos estressores do dia a dia e também por gerar diretamente experiências positivas associadas ao bemestar. Tanto o suporte de colegas de trabalho quanto o suporte do chefe podem influenciar emoções vivenciadas no dia a dia organizacional. Além disso, o apoio da chefia poderia ser um importante caminho para que o trabalhador desenvolvesse seus potenciais e tivesse experiências de realização pessoal.

Com base em tais suposições, foram traçadas três hipóteses.

Hipótese 1a: Os fatores de gestão de desempenho, suporte material e ascensão, promoção e salários da percepção de suporte organizacional e os dois fatores de suporte social terão impacto positivo nos fatores de afeto positivo e realização e impacto negativo no fator de afeto negativo. $O$ fator de carga de trabalho do suporte organizacional terá impacto negativo nos fatores de afeto positivo e realização e impacto positivo no fator de afeto negativo. Em resumo, espera-se que quanto mais positivas sejam as percepções de suporte organizacional e suporte social, maior seja o bem-estar no trabalho.

Apesar de a relação positiva entre percepção de suporte organizacional e de suporte social com o bem-estar ser esperada, é provável que cada um dos fatores do bem-estar no trabalho seja mais fortemente influenciado por determinados tipos de suporte. Essa variação é decorrente do conteúdo de cada dimensão do suporte organizacional e social e da natureza das dimensões hedônica e eudaimônica do bem-estar no trabalho. Por exemplo, o fator gestão de desempenho envolve práticas que incluem estabelecimento de metas, valorização de novas ideias e atualização dos funcionários para uso de novas tecnologias. Todas elas favorecem o desenvolvimento das habilidades e potenciais do trabalhador, que consistem em aspectos centrais na definição do fator de realização do bem-estar no 
trabalho. Com base nos estudos que sugerem que a experiência eudaimônica costuma ser acompanhada de afeto positivo (Nix, Ryan, Manly, \& Deci, 1999; Waterman et al., 2008), esta última variável deve também ser favorecida pela gestão do desempenho de modo similar ao que ocorre com o fator realização.

As ações envolvidas no fator gestão de desempenho do suporte organizacional parecem ser as mais favoráveis para a experiência de realização e, consequentemente, de afeto positivo no trabalho. Assim, é esperado que:

Hipótese 1b: Os fatores de realização e afeto positivo do bem-estar no trabalho serão mais fortemente preditos pela gestão de desempenho.

O afeto negativo, por sua vez, pode ser mais fortemente influenciado pelo fator carga de trabalho do suporte organizacional. A literatura do estresse ocupacional tem demonstrado que a sobrecarga de trabalho consiste em um dos principais determinantes do fenômeno de strain, que reflete emoções negativas do trabalhador, como tensão, ansiedade, desgaste e depressão (Jex, 1998). Com base nos estudos dos estressores e emoções negativas, é esperado que:

Hipótese 1c: $\mathrm{O}$ fator afeto negativo do bem-estar no trabalho será mais fortemente predito pela carga de trabalho.

A seguir, é descrito o método utilizado para o teste das hipóteses propostas.

\section{MÉTODO}

\section{Amostra}

Os participantes do estudo foram recrutados entre funcionários de uma organização pública localizada no Distrito Federal. Inicialmente, foram considerados os questionários respondidos de 406 participantes. Após a eliminação de casos omissos e o teste de pressupostos para as análises estatísticas foram mantidos 403 respondentes. Dentre aqueles que indicaram o sexo, 56,1\% eram mulheres e $42,9 \%$ eram homens. A média de idade dos respondentes foi de 38,49 anos $(\mathrm{dp}=8,83)$ e o tempo médio de serviço na organização foi de 10,82 anos $(\mathrm{dp}=7,80)$. Quanto à função desempenhada, os respondentes relataram ocupar cargos técnicos $(42,2 \%)$, cargos de analista $(23,6 \%)$, cargos de chefia $(5,5 \%)$ e cargos variados, como jornalistas, recepcionistas, médicos e assessores. Todos os respondentes faziam parte do quadro de servidores efetivos da organização e haviam ingressado por meio de concurso público.

\section{Instrumento}

Neste estudo foi utilizado um questionário composto por dois instrumentos: Escala de Bem-Estar no Trabalho [EBET] e Escala de Suporte Organizacional Percebido [ESOP]. A EBET (Paschoal \& Tamayo, 2008) foi escolhida, porque possui bons parâmetros psicométricos e aborda tanto a dimensão afetiva do bem-estar no trabalho quanto a dimensão eudaimônica de realização e expressão. Este instrumento é composto por 30 itens divididos em três fatores: (1) afeto positivo, com nove itens e índice de confiabilidade alpha de Cronbach $(\alpha)$ equivalente a 0,95; (2) afeto negativo, com 12 itens e $\alpha$ de 0,94 ; (3) realização, composto por nove itens e $\alpha$ igual a 0,92 .

A parte da EBET que se refere ao afeto no trabalho apresenta a seguinte instrução: nos últimos seis meses, meu trabalho tem-me deixado. Os itens, como alegre, orgulhoso, animado, irritado, chateado e nervoso, devem ser respondidos de acordo com uma escala de cinco pontos, que varia de 1 (nem um pouco) a 5 (extremamente). A parte de realização no trabalho contém a instrução: neste 
trabalho. Itens como realizo o meu potencial, avanço nas metas que estabeleci para minha vida e expresso o que há de melhor em mim devem ser respondidos de acordo com uma escala de concordância de cinco pontos, que varia de 1 (discordo totalmente) a 5 (concordo totalmente).

A ESOP, validada por Tamayo, Pinheiro, Tróccoli e Paz (2000), foi utilizada para avaliar a percepção de suporte organizacional e de suporte social. Este instrumento foi escolhido por dois motivos principais. Primeiramente, apesar de aludirem a construtos distintos, os itens que medem as dimensões do suporte organizacional e as dimensões do suporte social são abordados no mesmo instrumento. Em segundo lugar, a escala possui bons parâmetros psicométricos. A ESOP é composta por 42 itens divididos em seis fatores: (1) gestão organizacional do desempenho, composto por seis itens e $\alpha$ de 0,83 ; (2) sobrecarga de trabalho, com sete itens e $\alpha$ igual a 0,76 ; (3) percepção de suporte material, com sete itens e $\alpha$ de 0,82 ; (4) política de pagamento e desenvolvimento, referente à percepção de ascensão, promoção e salários, composto por cinco itens e $\alpha$ de 0,75 ; (5) estilo de gestão da chefia, com 11 itens e $\alpha$ igual a 0,84 ; (6) suporte social do grupo, com seis itens e $\alpha$ de 0,82 .

Os itens deste instrumento devem ser respondidos de acordo com uma escala de frequência de cinco pontos, que varia de 1 (nunca) a 5 (sempre).

\section{Procedimento de Coleta de Dados}

Os questionários foram aplicados coletivamente, durante o expediente de trabalho. O pesquisador ou o colaborador para a coleta de dados entrava nas salas de trabalho, explicava os objetivos do estudo e questões referentes ao sigilo e distribuía os questionários para os participantes. Os questionários eram respondidos e colocados em um envelope que, no final da aplicação, era recolhido pelo pesquisador.

\section{Procedimentos de Análise de Dados}

A variável dependente do estudo consiste no bem-estar no trabalho e está composta por três fatores: afeto positivo, afeto negativo e realização. As variáveis independentes consistem nos quatro fatores de percepção de suporte organizacional e nos dois fatores de suporte social no trabalho. Para o pressuposto de normalidade, foram avaliados os valores de skewness e kustosis dos erros padronizados, que apontaram resultados satisfatórios (maior valor para skewness igual a 0,66 e maior valor para kustosis igual a -0,39). Os princípios de linearidade e homocedasticidade dos resíduos também foram verificados graficamente.

Após o teste de pressupostos para a regressão e análises preliminares, as variáveis dependentes e independentes foram descritas por meio de medidas de centralidade e dispersão. As relações entre as variáveis dependentes e independentes foram inicialmente exploradas por meio das análises de correlação bivariada simples e, posteriormente, foi utilizada regressão múltipla padrão.

\section{RESULTADOS}

Os testes de pressupostos para regressão indicaram a presença de multicolinearidade entre os fatores de suporte social. Tal fenômeno foi verificado por meio dos valores de tolerância e variance inflation factor [VIF]. O fenômeno da colinearidade ocorre quando, num cálculo de regressão, a correlação entre duas ou mais variáveis independentes é muito alta, o que aumenta o erro padrão. Diante de tal resultado, foi conduzida uma análise fatorial para testar a distribuição dos itens nos fatores propostos por Tamayo et al. (2000) e verificar se alguns dos fatores poderiam ser agrupados. Não foi objetivo do presente estudo validar o instrumento de suporte, que já foi testado por Tamayo et al. (2002). Apenas foi verificada a estrutura dos itens mediante o indicativo de multicolinearidade. Na análise fatorial, foi utilizado o método Principal Axis Factoring [PAF] com rotação oblíqua. 
Os resultados demonstraram que os itens de gestão de chefia e de suporte social recebido dos colegas agruparam-se em um único fator, que foi denominado no presente estudo de suporte social. De acordo com autores diversos (Cooper, Dewe, \& O’Discoll, 2001; Winnubst, Buunk, \& Marcelinen, 1988), o apoio social recebido no trabalho manifesta-se por meio das relações de cooperação e compreensão entre os colegas e da atenção e reconhecimento gerencial. Pelo menos para a amostra do presente estudo, não houve diferenciação clara do agente do apoio social. Apoio dos colegas e apoio da chefia parecem ser percebidos de forma similar, constituindo um único núcleo ou uma única dimensão de apoio social. O novo fator de suporte social ficou composto por 16 itens e apresentou alpha de Cronbach de 0,92. Os fatores de suporte organizacional, por sua vez, mantiveram a estrutura e a confiabilidade encontradas por Tamayo et al. (2000).

Quanto aos itens de bem-estar no trabalho, os resultados encontrados por Paschoal e Tamayo (2008) no estudo de validação da EBET foram confirmados. A estrutura de três fatores e os altos índices de confiabilidade foram sustentados.

Em relação ao afeto positivo, a média para a amostra foi de $2,96(\mathrm{dp}=0,96)$, em uma escala de 1 a 5. Para afeto negativo, foi encontrada média de $1,87(\mathrm{dp}=0,83)$ e para o fator de realização, a média foi de $3,38(\mathrm{dp}=0,85 ;)$.

Em relação às variáveis independentes, a percepção de suporte é maior para o fator de suporte material $(\mathrm{M}=4,09$; dp =0,59), que indica a adequação e a qualidade de recursos materiais e financeiros oferecidos pela organização para a execução das tarefas de trabalho. $O$ fator que obteve menor pontuação foi a gestão de desempenho $(\mathrm{M}=3,21 ; \mathrm{dp}=0,70)$. Ainda assim, a média para o fator de gestão ficou acima do ponto médio da escala de resposta. Para ascensão, promoção e salários, foi encontrada média de $3,39(\mathrm{dp}=0,87)$. Para carga de trabalho, a média foi de $2,51(\mathrm{dp}=0,71)$. A média para a percepção de suporte social foi de 3,64 $(\mathrm{dp}=0,64)$.

Foram verificadas as correlações entre cada fator do bem-estar e as variáveis independentes do estudo. Todas as correlações entre as variáveis dependentes e independentes foram significativas $(\mathrm{p}<0,01)$. Entre todas as variáveis independentes, a gestão de desempenho apresentou as correlações mais fortes com afeto positivo $(r=0,47)$ e realização $(r=0,45)$. No caso do afeto negativo, as correlações mais fortes foram observadas para a gestão do desempenho $(r=0,42)$ e a carga no trabalho $(\mathrm{r}=0,41)$. Os resultados são apresentados na Tabela 1 .

Tabela 1

Correlações entre os Fatores de Bem-estar e as Variáveis Independentes

\begin{tabular}{lccc}
\hline \multicolumn{1}{c}{ Variável } & Afeto positivo & Afeto negativo & Realização \\
\hline Suporte material & $0,19^{* *}$ & $-0,19^{* *}$ & $0,13^{* *}$ \\
Gestão do desempenho & $0,47^{* *}$ & $-0,42^{* *}$ & $0,45^{* *}$ \\
Ascensão, promoção e salários & $0,24^{* *}$ & $-0,19^{* *}$ & $0,23^{* *}$ \\
Carga no trabalho & $-0,31^{* *}$ & $0,41^{* *}$ & $-0,17^{* *}$ \\
Suporte social & $0,45^{* *}$ & $-0,39^{* *}$ & $0,43^{* *}$ \\
\hline
\end{tabular}

A fim de seguir a investigação das relações entre as diferentes variáveis independentes e o bem-estar no trabalho, foi conduzida uma regressão múltipla padrão para cada variável dependente. Na regressão múltipla padrão, as variáveis independentes entram na equação de regressão de uma única vez e cada uma delas é avaliada quanto ao que acrescenta para a predição da variável dependente (Tabachnick \& Fidell, 1996). Primeiramente, foi conduzida a regressão do suporte organizacional e social sobre a realização no trabalho. 
A Tabela 2 apresenta os coeficientes de regressão não padronizados (B) e intercepto, os coeficientes de regressão padronizados $(\beta)$, o R2 e o R2 ajustado. O R para a regressão foi significativamente diferente de zero, $\mathrm{F}(5,402)=27,383, \mathrm{p}<0,001$.

Tabela 2

Regressão Padrão do Suporte Organizacional e Social sobre a Realização

\begin{tabular}{lcc}
\hline Variáveis Preditoras & B & $\boldsymbol{\beta}$ \\
\hline Suporte Material & $-0,13$ & $-0,09$ \\
Gestão de Desempenho & $0,37^{* * *}$ & 0,31 \\
Ascensão, promoção e salários & 0,08 & 0,08 \\
Carga no trabalho & $-0,02$ & $-0,01$ \\
Suporte Social & $0,32^{* * *}$ & 0,26
\end{tabular}

Intercepto $=1,222$

$$
\begin{aligned}
& \underline{\mathrm{R}}^{2}=0,26 \\
& \underline{\mathrm{R}}^{2} \text { ajustado }=0,25 \\
& \underline{\mathrm{R}}=0,51
\end{aligned}
$$

Nota. $* * * p<0,001$

Duas das cinco variáveis independentes explicaram $26 \%$ da realização no trabalho. São elas: gestão de desempenho e suporte social. A gestão de desempenho foi a que apresentou maior poder explicativo. A relação entre as variáveis independentes apontadas e a realização foi positiva, o que quer dizer que quanto mais positiva a percepção da gestão de desempenho e de suporte social, maior realização é vivenciada no trabalho.

Em seguida, foi conduzida uma regressão múltipla padrão do suporte organizacional e social sobre o afeto positivo. A Tabela 3 apresenta os coeficientes de regressão não padronizados (B) e intercepto, os coeficientes de regressão padronizados $(\beta), o R^{2}$ e $o R^{2}$ ajustado. $O R$ para a regressão foi significativamente diferente de zero, $F(5,402)=33,260$, $p<0,001$.

Tabela 3

\section{Regressão Padrão do Suporte Organizacional e Social sobre o Afeto Positivo}

\begin{tabular}{lcc}
\hline Variáveis Preditoras & B & $\boldsymbol{\beta}$ \\
\hline Suporte Material & $-0,10$ & $-0,06$ \\
Gestão de Desempenho & $0,41^{* * *}$ & 0,30 \\
Ascensão, promoção e salários & 0,07 & 0,06 \\
Carga no trabalho & $-0,19^{* *}$ & $-0,14$ \\
Suporte Social & $0,32^{* * *}$ & 0,23
\end{tabular}

Intercepto $=1,152$

$$
\begin{aligned}
& \underline{\mathrm{R}}^{2}=0,29 \\
& \underline{\mathrm{R}}^{2} \text { ajustado }=0,28 \\
& \underline{\mathrm{R}}=0,54
\end{aligned}
$$

Nota. ${ }^{* *} \mathrm{p}<0,01 * * * \mathrm{p}<0,001$ 
Das cinco variáveis do modelo, três contribuíram significativamente com $29 \%$ da explicação do afeto positivo. A variável que mais contribui para o modelo foi a gestão de desempenho. Com exceção da variável carga no trabalho, que se relacionou negativamente com o afeto positivo, as outras relações foram positivas. Quanto mais positiva a percepção da gestão de desempenho e de suporte social, maior o afeto positivo no trabalho; quanto maior a percepção de sobrecarga de trabalho, menor o afeto positivo.

Por fim, foi conduzida uma regressão múltipla padrão do suporte organizacional e do suporte social sobre o afeto negativo. A Tabela 4 apresenta os coeficientes de regressão não padronizados (B) e intercepto, os coeficientes de regressão padronizados $(\beta)$, o R2 e o R2 ajustado. O R para a regressão foi significativamente diferente de zero, $F(5,402)=31,022$, $p<0,001$.

Tabela 4

Regressão Padrão do Suporte Organizacional e Social sobre o Afeto Negativo

\begin{tabular}{lll}
\hline Variáveis Preditoras & B & $\boldsymbol{\beta}$ \\
\hline Suporte Material & 0,02 & 0,05 \\
Gestão de Desempenho & $-0,10^{* * *}$ & $-0,26$ \\
Ascensão, promoção e salários & 0,00 & $-0,01$ \\
Carga no trabalho & $0,12^{* * *}$ & 0,29 \\
Suporte Social & $-0,06^{* *}$ & $-0,15$
\end{tabular}

Intercepto $=1,522$

$\underline{\mathrm{R}}^{2}=0,28$

$\underline{\mathrm{R}}^{2}$ ajustado $=0,27$

$\underline{\mathrm{R}}=0,53$

Nota. ${ }^{* *} \mathrm{p}<0,01 * * * \mathrm{p}<0,001$

Das cinco variáveis do modelo, três contribuíram significativamente para predizer $28 \%$ do afeto negativo: gestão de desempenho, sobrecarga no trabalho e suporte social. A variável que mais contribuiu para o modelo foi a carga no trabalho, seguida pela gestão de desempenho. A carga de trabalho relacionou-se positivamente com o afeto negativo: indica que, quanto maior a percepção de sobrecarga, maior o afeto negativo no trabalho. A gestão de desempenho e o suporte social relacionaram-se negativamente com o afeto negativo, o que revela que quanto mais positiva é a percepção da gestão de desempenho e de suporte social, menos afeto negativo é vivenciado pelo trabalhador.

\section{DISCUSSÃo}

Os resultados das análises descritivas indicaram considerável percepção positiva de suporte organizacional e social. A percepção do fator gestão de desempenho, que obteve a pontuação média mais baixa entre os fatores de suporte organizacional e social $(\mathrm{M}=3,21 ; \mathrm{dp}=0,70)$, manteve-se acima do ponto médio da escala de resposta que variava de 1 a 5 . Na percepção dos respondentes, a organização tem retribuído os esforços de seus membros adequadamente. Além disso, colegas e chefes têm oferecido apoio satisfatório aos integrantes de seus grupos.

Assim como a percepção de suporte organizacional e social, os resultados das análises descritivas para o bem-estar no trabalho indicaram pontuações médias acima do ponto médio das escalas de 
respostas para o fator realização $(\mathrm{M}=3,38 ; \mathrm{dp}=0,85)$ e afeto positivo $(\mathrm{M}=2,96 ; \mathrm{dp}=0,96)$. Para $\mathrm{o}$ afeto negativo, a pontuação média foi abaixo do ponto médio da escala de resposta $(\mathrm{M}=1,87 ; \mathrm{dp}=$ 0,83 ). É possível afirmar que, no geral, os trabalhadores investigados têm experiências significativas de felicidade. Tais resultados sustentam a ideia de que o contexto de trabalho se apresenta como lugar privilegiado de emoções e, fundamentalmente, de realização e de construção da felicidade pessoal. Nem sempre o trabalho foi considerado sob essa perspectiva. Com o aumento da competitividade e das novas demandas do ambiente de trabalho, as organizações têm-se preocupado em valorizar seus empregados e criar as condições necessárias para o seu bom desempenho e satisfação. A premissa de que o alcance da felicidade pessoal é possível no trabalho impele os profissionais de gestão de pessoas a identificar estratégias eficazes na promoção do bem-estar.

Quanto às relações entre as variáveis, a primeira hipótese proposta neste estudo referia-se ao impacto direto do suporte organizacional e social sobre o bem-estar no trabalho e considerava que quanto mais positiva fosse a percepção de suporte, maior seria o bem-estar. De forma mais detalhada, era esperado que os fatores gestão de desempenho, suporte material e ascensão, promoção e salários da percepção de suporte organizacional e os fatores de suporte social tivessem impacto positivo no afeto positivo e realização e impacto negativo no afeto negativo. Esperava-se ainda que o fator carga de trabalho do suporte organizacional tivesse impacto negativo no afeto positivo e realização e positivo no afeto negativo. Os resultados sustentaram parcialmente a primeira hipótese proposta, já que apenas os fatores gestão de desempenho, suporte social e carga de trabalho contribuíram significativamente para a explicação do bem-estar.

As outras duas hipóteses propunham que, devido à variação do conteúdo de cada dimensão de suporte e da natureza das dimensões hedônica e eudaimônica do bem-estar no trabalho, cada um dos fatores da variável dependente seria mais fortemente influenciado por um tipo específico de suporte. A Hipótese $1 \mathrm{~b}$ propunha que, entre os fatores de suporte organizacional e social, gestão de desempenho seria o preditor mais forte do afeto positivo e da realização. Para o afeto negativo, a Hipótese 1c propunha que a carga no trabalho seria o preditor mais forte. Ambas as hipóteses receberam apoio dos resultados.

Para a explicação do afeto positivo, a gestão do desempenho, o suporte social e a carga no trabalho compuseram o modelo de preditores. Os resultados indicaram que quanto mais positiva é a percepção de gestão de desempenho e de suporte social, mais afeto positivo é vivenciado no trabalho e quanto maior a percepção de sobrecarga, menos afeto positivo é vivenciado. Os resultados da regressão dos fatores de suporte sobre a realização revelaram que a gestão do desempenho e o suporte social entraram no modelo de preditores. Quanto mais positiva é a percepção de gestão de desempenho e de suporte social no trabalho, maior é a realização no trabalho. Tanto para realização quanto para o afeto positivo, a gestão do desempenho foi o principal preditor.

Waterman (1993) afirma que toda experiência eudaimônica costuma ser acompanhada de afeto positivo. Para o desenvolvimento da Hipótese $1 \mathrm{~b}$, considerou-se que características do trabalho favoráveis à experiência eudaimônica teriam também importante influência no afeto positivo. $\mathrm{O}$ suporte organizacional relacionado à gestão de desempenho envolve práticas que incluem estabelecimento de metas, valorização de novas idéias e atualização dos funcionários para uso de novas tecnologias. Ações organizacionais como manter coerência entre diretrizes, metas e ações, levar em conta a opinião dos funcionários para resolver problemas, divulgar metas de desempenho esperadas e investir no treinamento dos funcionários são indicadores deste tipo de suporte e também favoráveis ao desenvolvimento das habilidades e dos potenciais do trabalhador. Conseqüentemente, o suporte voltado à gestão de desempenho aumenta o afeto positivo no trabalho.

Para a explicação do afeto negativo, a gestão do desempenho, o suporte social e a carga no trabalho entraram no modelo de preditores da regressão múltipla padrão. Os resultados indicaram que quanto mais positiva é a percepção de gestão de desempenho e de suporte social, menos afeto negativo é vivenciado no trabalho; e quanto maior a percepção de sobrecarga, mais afeto negativo é experimentado pelo trabalhador. O principal preditor do afeto negativo foi a carga no trabalho. 
Tanto o afeto positivo quanto o afeto negativo são compostos por emoções e humores e consistem em uma dimensão de natureza essencialmente hedônica. Apesar disso, o papel de cada variável independente no modelo explicativo foi diferente para os dois casos. A carga de trabalho foi o principal preditor do afeto negativo e teve peso muito menor na explicação do afeto positivo, ficando atrás da gestão do desempenho e do suporte social.

Os estudos no campo do estresse ocupacional têm consistentemente demonstrado que estímulos estressores influenciam emoções negativas dos trabalhadores (Mackie, Holahan, \& Gottlieb, 2001; Wang \& Patten, 2001). As próprias reações iniciais associadas aos estressores organizacionais são de natureza emocional (Cooper \& Cartwright, 2001; Stanley \& Burrows, 2001). Dentre os principais estressores organizacionais, a literatura aponta a sobrecarga de trabalho. Quando as ações organizacionais geram demandas quantitativamente ou qualitativamente excessivas para o trabalhador, as emoções negativas tendem a se intensificar (Jex, 1998). O campo do estresse não enfoca emoções positivas no trabalho. Os resultados do presente estudo revelam que as emoções positivas também recebem impacto de um dos principais estressores organizacionais, mas são mais fortemente explicadas por outro fator do suporte organizacional.

Em primeiro lugar, esse achado sustenta que o afeto negativo é mais suscetível a eventos organizacionais considerados estressores do que o afeto positivo. Em segundo lugar, sugere que afeto positivo e negativo não consistem somente em dimensões independentes (Albuquerque \& Troccoli, 2004; Watson, Clark, \& Tellegen, 1988), mas variam com intensidades distintas, mediante as mesmas características e condições laborais. A falta de suporte na forma de sobrecarga tem impacto maior na dimensão hedônica de conteúdo negativo.

Em relação ao suporte social, que compôs o modelo explicativo de todas as variáveis independentes, a literatura tem demonstrado que esse fenômeno exerce um efeito benéfico na saúde mental e no bemestar pessoal. A colaboração entre os colegas na realização do trabalho, o apoio mútuo para resolver dificuldades no trabalho, a preocupação com o bem-estar dos colegas, a colaboração do chefe na resolução de problemas pessoais dos funcionários e a consideração das críticas dos subordinados por parte do chefe são exemplos de ações que aumentam o afeto positivo do trabalhador, diminuem a vivência de afeto negativo no trabalho e ainda podem contribuir para as experiências de expressão pessoal e realização.

O suporte social pode ter efeito direto no bem-estar, pois previne a exposição a certos tipos de estressores ambientais. As relações sociais ajudam o sujeito a antecipar certos estressores e alterar aspectos do ambiente ou da sua própria conduta. Além disso, o suporte social pode moderar efeitos patogênicos de estressores de natureza social e caracteriza-se como protetor do impacto de condições adversas (Barrón, 1992).

Em relação aos fatores de suporte material e ascensão, promoção e salários do suporte organizacional, ambos apresentaram baixas correlações, apesar de significativas, com os fatores de bem-estar no trabalho. Além disso, esses dois fatores não entraram no modelo explicativo do bemestar no trabalho encontrado na regressão múltipla padrão.

O suporte material indica que a organização se engaja na modernização e dinamização dos processos de trabalho e na qualificação dos seus funcionários. Adquirir equipamentos modernos de trabalho, fornecer equipamentos necessários ao desempenho eficaz e oferecer materiais em quantidade suficiente são exemplos de ações que demonstram a qualidade do suporte material oferecido aos trabalhadores. $\mathrm{O}$ suporte organizacional relacionado às práticas de ascensão, promoção e salários depende de ações organizacionais como oferecer oportunidades de ascensão profissional e pagamento de salários dignos.

Conforme assinalado por Warr $(1987,2007)$, características de trabalho como salários, desenvolvimento na carreira e aspectos do contexto físico têm impacto no bem-estar quando são percebidas negativamente ou num nível muito baixo pelo trabalhador. Na medida em que os salários e 
o contexto físico são adequados e as possibilidades de desenvolvimento na carreira se tornam presentes no contexto laboral, o impacto dessas condições no bem-estar deixa de ser significativo.

Os resultados encontrados no presente estudo oferecem suporte à proposta de Warr $(1987,2007)$. O suporte material e o suporte para ascensão e salários apresentaram baixas correlações, tanto com a dimensão hedônica quanto com a dimensão eudaimônica do bem-estar no trabalho e não se sustentaram como preditores em nenhuma das regressões conduzidas. As análises descritivas indicaram ainda que o suporte material foi a dimensão do suporte organizacional percebida mais positivamente pelos participantes do estudo; e o fator de ascensão e salários obteve pontuação média acima do ponto médio da escala de resposta. As condições de trabalho representadas pelos dois fatores de suporte em questão parecem estar presentes na organização e são percebidas positivamente pelos funcionários.

É possível que em uma amostra que relatasse baixos níveis de suporte material e de suporte vinculado ao salário e às práticas de ascensão, o bem-estar sofresse também o impacto dessas condições. Como já foi discutida anteriormente, a situação relatada pela amostra investigada é diferente e a afirmação anterior pode ser mais bem sustentada com estudos adicionais.

Outra questão envolvida nos resultados sobre o suporte material refere-se ao acesso que os funcionários têm aos recursos e equipamentos de trabalho. Independentemente do desempenho individual, todos recebem condições físicas de trabalho equivalentes e materiais de qualidade. É possível que em uma organização que adotasse práticas de gestão com foco no desempenho e a distribuição de recursos e materiais de qualidade estivesse condicionada a algum critério avaliativo, o fator de suporte material tivesse alguma influência no bem-estar.

Muitos autores têm apontado a importância de variáveis contextuais na predição do bem-estar e de fenômenos relacionados a ele (Jex, 1998; Pollard, 2001; Totterdell et al., 2004; Warr, 2007; Williams et al., 1991). Por um lado, os resultados encontrados no papel preditivo do suporte organizacional e do suporte social convergem com estudos teóricos e empíricos do campo do bem-estar que apontam as características e condições do contexto laboral como variáveis independentes importantes. Por outro lado, o presente estudo aprofunda a investigação de dois tipos específicos de variáveis organizacionais percebidas e explora seu impacto sobre as duas dimensões centrais do bem-estar no trabalho.

Em relação ao suporte organizacional, este tem-se revelado um bom preditor de vínculos do trabalhador com a organização (Borges-Andrade \& Pilatti, 2001; Eisenberg et al., 1986; Siqueira, 1995). O presente estudo constatou que tal variável organizacional percebida, especialmente a gestão de desempenho e a carga de trabalho, é também um bom preditor do bem-estar no trabalho, construto composto por dimensões hedônica e eudaimônica.

Pesquisas das variáveis situacionais percebidas e afeto no trabalho indicam correlações de semelhante ou menor intensidade entre as variáveis. Por exemplo, os resultados da metanálise conduzida por Barsky e Kaplan (2007) sobre a associação da justiça organizacional com o afeto no trabalho indicaram valores de correlação entre 0,20 a 0,31 . Totterdell et al. (2004) verificaram que o tamanho da rede social no ambiente de trabalho teve correlação de 0,20 com o entusiasmo e de 0,25 com a ansiedade de trabalhadores. No estudo de Silva (2007), a correlação mais forte entre valores organizacionais e afeto positivo foi de $-0,20$. No presente estudo, a correlação da gestão do desempenho com o afeto positivo foi de 0,47 ; a correlação com o afeto negativo foi de $-0,41$. A sobrecarga apresentou correlação de $-0,31 \mathrm{com}$ afeto positivo e de $0,41 \mathrm{com}$ afeto negativo. Quanto à realização, a correlação com gestão do desempenho foi de 0,45 , mas não é possível estabelecer comparações com outros estudos, porque o elemento eudaimônico do bem-estar ainda é pouco investigado. 


\section{CONCLUSÕES}

Este estudo abordou variáveis situacionais e pessoais que ainda não haviam sido relacionadas com o bem-estar no trabalho, especialmente no que diz respeito aos seus elementos hedônicos e eudaimônicos. Foi constatado um impacto diferenciado das variáveis independentes sobre cada uma das variáveis dependentes. Em termos teóricos, tal achado sustenta a importância da inclusão de elementos com clara conotação positiva na definição de bem-estar, em oposição à tradição que o define a partir da ausência de experiências negativas. Além disso, os resultados indicaram que suporte organizacional e suporte social consistem em variáveis promissoras e importantes para a compreensão de experiências subjetivas positivas no trabalho.

Em termos práticos, a verificação de que condições organizacionais têm impacto direto e forte sobre diferentes elementos do bem-estar pode ajudar no planejamento de intervenções nos locais de trabalho. $\mathrm{O}$ modo e a força com que as variáveis independentes se associam com o afeto negativo, o afeto positivo e a realização indicam que os programas de promoção de bem-estar no trabalho devem considerar estratégias diferenciadas em função do foco de intervenção adotado. Dentre as variáveis independentes do presente estudo, a sobrecarga consiste no principal preditor do afeto negativo, mas não exerce influência sobre a realização. Se o foco de uma intervenção consiste, por exemplo, na diminuição ou controle do afeto negativo, devem ser alterados os elementos da carga de trabalho. Se o foco está na promoção do afeto positivo e da realização, aspectos relacionados à gestão do desempenho devem ser priorizados.

Apesar da crescente preocupação com o estudo científico da felicidade, as pesquisas do bem-estar relativo ao contexto laboral ainda são escassas. Nesse campo em construção, a divergência e a falta de clareza acerca das definições do bem-estar no trabalho é um ponto que se destaca. O presente estudo contribuiu especialmente para a conceituação do bem-estar no trabalho e demonstrou que este fenômeno pode ser compreendido em torno de duas dimensões: hedônica e eudaimônica. Prevalência de emoções positivas, desenvolvimento de potências individuais e avanço nas metas de vida podem não contemplar todo o fenômeno do bem-estar pessoal ou felicidade, que consiste num construto complexo, mas representam elementos centrais para sua definição.

Um desafio teórico importante diz respeito ao próprio conteúdo e à estrutura do bem-estar no trabalho. Nota-se a existência de um viés cultural na definição de bem-estar. A importância atribuída à intensidade das emoções positivas e a própria definição da felicidade são culturalmente sensíveis. A dimensão eudaimônica do bem-estar, por exemplo, focaliza a expressão e a realização de potenciais do próprio indivíduo e o avanço nas metas de vida pessoalmente importantes. O conteúdo dos elementos eudaimônicos é nitidamente focado no self e na preocupação do indivíduo consigo mesmo. A literatura revisada sobre o bem-estar baseia-se na sociedade ocidental contemporânea. Pesquisas adicionais devem ser conduzidas comparando diferentes culturas e mesmo cidades e regiões do país. Além disso, devem ser testadas as diferenças quanto ao gênero, idade e funções assumidas pelos trabalhadores. Homens e mulheres percebem a felicidade da mesma forma? Diferenças geracionais influenciam a felicidade? Pessoas que ocupam diferentes funções e são alvos de políticas de recursos humanos diferenciadas percebem a felicidade de modo semelhante? Todas essas questões ainda carecem de dados consistentes.

Uma limitação do presente estudo consiste na dificuldade de generalização dos resultados encontrados. A pesquisa foi conduzida em uma única organização pública do Distrito Federal. Amostras representativas de outros contextos organizacionais poderiam contribuir para o teste das suposições apontadas na discussão. Além disso, o presente estudo focou as percepções dos trabalhadores e abordou as variáveis independentes no nível individual apenas. Pesquisas futuras poderiam utilizar um delineamento multinível, para testar o impacto de variáveis organizacionais sobre o bem-estar no trabalho.

Artigo recebido em 17.07.2009. Aprovado em 29.06.2010. 


\section{REFERÊNCIAS BIBLIOGRÁFICAS}

Albuquerque, A. S., \& Tróccoli, B. T. (2004). Desenvolvimento de uma escala de bem-estar subjetivo. Psicologia: Teoria e Pesquisa, 20(2), 153-164.

Barrón, A. (1992). Apoyo social y salud mental. In J. L. Alvaro, J. R. Torregrosa, \& A. G. Luque (Orgs.), Influencias sociales y psicológicas en la salud mental (pp. 223-233). Madrid: Siglo XXI de España Editores.

Barsky, A., \& Kaplan, S. A. (2007). If you feel bad, it's unfair: a quantitative synthesis of affect and organizational justice perceptions. Journal of Applied Psychology, 92(1), 286-295.

Beehr, T. A. (1998). Research on occupational stress: an unfinished enterprise. Personnel Psychology, 51(4), 835-844.

Borges-Andrade, J. E., \& Pillati, R. (2001). Comprometimento atitudinal e comportamental: relações com suporte e imagem nas organizações. Revista de Administração Contemporânea, 5(3), 85106.

Codo, W. (1999). Um diagnóstico do trabalho (em busca do prazer). In A. Tamayo, J. E. BorgesAndrade, \& W. Codo (Orgs.), Trabalho, organizações e cultura (pp. 21-40). São Paulo: Cooperativa de Autores Associados.

Cooper, C. L., \& Cartwritgh, S. (2001). Organizational management of stress and destructive emotions at work. In R. L. Payne \& C. L. Cooper (Orgs.), Emotions at work. Theory, research and applications for management (pp. 269-280). Chichester: John Wiley \& Sons.

Cooper, C. L., Dewe, P., \& O'Discoll, M. P. (2001). Organizational stress. A Review and critique of theory, research, and applications. London: Sage.

Daniels, K. (2000). Measures of five aspects of affective well-being at work. Human Relations, 53(2), 275-294.

Deci, E. L., \& Ryan, R. M. (2008). Hedonia, eudaimonia, and well-being: an introduction. Journal of Happiness Studies, 9(1), 1-11.

Eisenberger, R., Huntington, R., Hutchison, S., \& Sowa, D. (1986). Perceived organizational support. Journal of Applied Psychology, 71(3), 500-507.

Estramiana, J. L. A. (1992). Desempleo y bienestar psicológico. Madrid: Siglo XXI de España Editores.

Horn, J. E. van, Taris, T. W., Schaufeli, W. B., \& Scheurs, P. J. G. (2004). The structure of occupational well-being: a study among Dutch teachers. Journal of Occupational and Organizational Psychology, 77, 365-375.

Jex, S. M. (1998). Stress and job performance. London: Sage Publications.

Kelloway, E. K., Gottlieb, B. H., \& Barham, L. (1999). The source, nature, and direction of work and family conflict: a longitudinal investigation. Journal of Occupational Health Psychology, 4(4), 337-346.

Mackie, K. S., Holahan, C. K., \& Gottlieb, N. H. (2001). Employee involvement management practices, work stress, and depression in employees of a human service residential care facility. Human Relations, 54(8), 1065-1092. 
Maslach, C., \& Jackson, S. (1986). Maslach Burnout inventory manual. Palo Alto: Consulting Psychological Press.

Nix, G. A., Ryan, R. M., Manly, J. B., \& Deci, E. L. (1999). Revitalization through self-regulation: the effects of autonomous and controlled motivation on happiness and vitality. Journal of Experimental Social Psychology, 35(3), 266-284.

Oliveira-Castro, G. A., Borges-Andrade, J. E., \& Pilati, R. (1999). Percepção de suporte organizacional: desenvolvimento e validação de um questionário. Revista de Administração Contemporânea, 3(2), 29-51.

Oliveira, P., \& Limongi-França, C. (2005). Avaliação da gestão de programas de qualidade de vida no trabalho. RAE Eletrônica, 4(1), 1-21. Recuperado em 10 outubro, 2007, de http://www.scielo.br/pdf/raeel/v4n1/v4n1a05.pdf

Paschoal, T., \& Tamayo, A. (2008). Construção e validação da escala de bem-estar no trabalho. Avaliação Psicológica, 7(1), 11-22.

Pinheiro, F. A. (2002). Aspectos psicossociais dos distúrbios osteomusculares relacionados ao trabalho - DORT/LER. Tese de doutorado, Universidade de Brasília, Brasília, DF, Brasil.

Pollard, T. M. (2001). Changes in mental well-being, blood pressure and total cholesterol levels during workplace reorganization: the impact of uncertainty. Work and stress, 15(1), 14-28.

Ryan, R. M., \& Deci, E. R. (2001). On happiness and human potentials: a review of research on hedonic and eudaimonic well-being. Annual Review of Psychology, 52, 141-166.

Ryff, C. D. (1989). Happiness is everything, or is it? Explorations on the meaning of psychological well-being. Journal of Personality and Social Psychology, 57(6), 1069-1081.

Seidl, E. M. F., \& Tróccoli, B. T. (2006). Desenvolvimento de escala para avaliação do suporte social em HIV/AIDS. Psicologia: Teoria e Pesquisa, 22(3), 317-326.

Seligman, M. E. P, \& Csikszentmihalyi, M. (2000). Positive psychology: an introduction. American Psychologist, 55(1), 5-14.

Silva, A. R. (2007). Influência dos valores humanos, tipo de julgamento e atribuição de significado na intenção de voto ao cargo de governador do Distrito Federal. Dissertação de mestrado, Universidade de Brasília, Brasília, DF, Brasil.

Siqueira, M. M. M. (1995). Antecedentes de comportamentos de cidadania organizacional: a análise de um modelo pós-cognitivo. Tese de doutorado, Universidade de Brasília, Brasília, DF, Brasil.

Stanley, R., \& Burrows, G. (2001). Varieties and functions of human emotion. In R. L. Payne \& C. L. Cooper (Orgs.), Emotions at work: theory, research and applications for management (pp. 319). Chichester: John Wiley and Sons.

Tabachnick, B. G, \& Fidell, L. S. (1996). Using multivariate statistics (3a ed.). New York: Harper Collins College Publishers.

Tamayo, M. R., Pinheiro, F. A., Tróccoli, B. T., \& Paz, M. G. T. (2000, julho). Construção e validação da escala de suporte organizacional percebido (ESOP). [Resumo]. Anais da Reunião Anual da SBPC, Brasília, DF, Brasil, 52.

Tamayo, M. R., \& Tróccoli, B. T. (2002). Exaustão emocional: relações com a percepção de suporte organizacional e com as estratégias de coping no trabalho. Estudos de Psicologia, 7(1), 37-46. 
Tiberius, V. (2004). Cultural differences and philosophical accounts of well-being. Journal of Happiness Studies, 5(3), 293-314.

Totterdell, P., Wall, T., Holman, D., Diamond, H., \& Epitropaki, O. (2004). Affect networks: a structural analysis of the relationship between work ties and job-related affect. Journal of Applied Psychology, 89, 854-867.

Wang, J. L., \& Patten, S. B. (2001). Perceived work stress and major depression in the Canadian employed population, 20-49 years old. Journal of Occupational Health Psychology, 6(4), 283289.

Warr, P. B. (1987). Work, unemployment and mental health. Oxford: Oxford Science Publication.

Warr, P. B. (2007). Work, happiness and unhappiness. New Jersey: Lawrence Erlbaum Associates.

Waterman, A. S. (1993). Two conceptions of happiness: contrasts of personal expressiveness (eudaimonia) and hedonic enjoyment. Journal of Personality and Social Psychology, 64(4), 678-691.

Waterman, A. S., Schwartz, S. J., \& Conti, R. (2008). The implications of two conceptions of happiness (hedonic enjoyment and eudaimonia) for the understanding of intrinsic motivation. Journal of Happiness Studies, 9(1), 41-79

Watson, D., Clark, L. A., \& Tellegen, A. (1988). Development and validation of brief measures of positive and negative affect: the PANAS scales. Journal of Personality and Social Psychology, 54(6), 1063-1067.

Weiss, H. M., Suckow, K., \& Cropanzano, R. (1999). Effects of justice conditions on discrete emotions. Journal of Applied Psychology, 84(5), 786-794.

Williams, K. J., Suls, J., Alliger, G. M., Learner, S. M., \& Wan, C. K. (1991). Multiple role juggling and daily mood states in working mothers: an experience sampling study. Journal of Applied Psychology, 76(5), 664-674.

Wilson, M. G., DeJoy, D. M., Vandenberg, R., Richardson, H. A., \& McGrath, A. L. (2004). Work characteristics and employee health and well-being: test of a model of healthy work organization. Journal of Occupational and Organizational Psychology, 77(4), 565-588.

Winnubst, J. A. M., Buunk, B. P., \& Marcelissen, F. H. G. (1988). Social support and stress: perspectives and processes. In S. Fisher \& J. Reason (Orgs.), Handbook of life stress, cognition and health (pp. 511-528). Chichester: Wiley and Sons. 